\title{
COMPARTIMENTAÇÃO DO RELEVO BASEADA EM PARÂMETROS MORFOMÉTRICOS: UMA PROPOSTA DE ÍNDICE GLOBAL DE DISSECAÇÃO DO RELEVO
}

\author{
Fabiano Érico Vieira de Souza ${ }^{(a)}$, Braúlio Magalhães Fonseca $^{(b)}$, Fernanda Mara Coelho Pizani $^{(\mathrm{c})}$ \\ (a) Departamento de Cartografia/IGC, UFMG, fabianoerico@ hotmail.com \\ (b) Departamento de Cartografia/IGC, UFMG, Professor Adjunto, brauliomagalhaes@ufmg.br \\ (c) Departamento de Cartografia/IGC, UFMG, fm.coelho@yahoo.com.br
}

Eixo: GEOTECNOLOGIAS E MODELAGEM ESPACIAL EM GEGRAFIA FÍSICA

\begin{abstract}
Resumo
A contribuição do geoprocessamento para o desenvolvimento dos estudos geomorfológicos vem crescendo nos últimos anos, por possibilitar a análise de vários elementos ou fenômenos de forma integrada, pela relativa facilidade de aquisição e manipulação de dados morfométricos em ambiente de Sistema de Informações Geográficas. No entanto, ainda carece de padronização e metodologias flexíveis e, aplicáveis a diferentes regiões. Este trabalho objetiva apresentar uma metodologia de compartimentação do relevo baseada em índices morfométricos, portanto, possui um viés quantitativo. O recorte da área de estudo situa-se na região da Serra do Curral e suas imediações, tendo uma escala de análise regional. Foram calculados o Índice de Concentração da Rugosidade, o Índice de Hack e a Densidade de Drenagem para compor o Índice Global de Dissecação do Relevo. Os resultados obtidos foram comparados com o mapeamento geomorfológico da APA Sul RMBH, realizado pelo CPRM, com o intuito de avaliar a adequação do modelo gerado com um produto cartográfico oficial gerado a partir de dados de campo.
\end{abstract}

Palavras chave: Compartimentação do reevo, Índices morfométricos, Geoprocessamento

\section{Introdução}

A formulação de índices e abstrações matemáticas em Geomorfologia faz parte dos procedimentos metodológicos desta ciência desde Horton (1945), o caráter prático e a aplicabilidade dos índices podem ser atestados até mesmo pela formação acadêmica dos seus propositores, em sua maioria oriundos da Engenharia (RODRIGUES, 1997).

A manipulação de dados em SIG e a criação de modelos vem sendo utilizadas para simular o comportamento sistêmico do ambiente, possibilitando análises de forma holística com a interação dos elementos da paisagem.

Dentro das geociências, em específico para os estudos geomorfológicos, as ferramentas de geoprocessamento possibilitam com facilidade a obtenção de dados morfométricos através dos Modelos digitais de Terreno - MDT e a partir destes, extrair diversas informações do relevo estudado. Permite também aplicar com rapidez e precisão álgebras matriciais, possibilitando diversas análises espaçotemporais dos processos geomorfológicos. 
OS DESAFIOS DA GEOGRAFIA FÍSICA NA FRONTEIRA DO CONHECIMENTO Instituto de Geociências - Unicamp

Campinas - SP

28 de Junho à 02 de Julho de 2017

No entanto, a complexidade e a variedade de objetos de estudo em Geomorfologia, conforme menciona Florenzano (2008), levam a uma consequente dificuldade de sua classificação. Além da falta de consenso metodológico e de conteúdo para realizar um mapeamento geomorfológico, a dificuldade de representação cartográfica das feições mapeadas em escala apropriada dificultam a elaboração de um método unificado de mapeamento.

O problema metodológico, segundo Augustin e Sampaio (2014) também advém da dificuldade de padronização das feições do relevo, uma vez que a maioria das metodologias possui caráter qualitativo e dependem do grau de conhecimento e experiência do pesquisador, que mesmo com o auxílio das geotecnologias, as tornam subjetivas.

Diante do exposto, este estudo pretende apresentar uma proposta metodológica para desenvolvimento de um Índice Global de Dissecação do Relevo, manipulados em ambiente SIG e obtidos através de ferramentas de geoprocessamento, um índice derivado da álgebra matricial envolvendo três outros índices geomorfológicos já consolidados na literatura, que delimita compartimentos de relevo considerando a densidade de drenagem, a concentração da rugosidade do relevo e o vigor energético dos canais de drenagem, estimado pela relação declividade-extensão.

\section{1 Área de Estudo}

A região de estudo contempla o alinhamento SW-NE do hogback da Serra do Curral, limite norte do Quadrilátero Ferrífero, pertencente a APA Sul RMBH e demais estruturas em suas imediações.

A área em estudo está inserida em uma das estruturas geológicas que compõem a província mineral do Quadrilátero Ferrífero - QF, localizada na porção central do Estado de Minas Gerais, onde posicionase no extremo sudeste no Cráton do São Francisco. O Quadrilátero possui cerca de $7.000 \mathrm{~km}^{2}$ e é uma das principais províncias minerais do país, tendo enorme importância científica e econômica para o Estado, uma vez que apresenta riquezas geológicas incomuns.

Sua consolidação se deu ao final do Ciclo Transamazônico e é limitado por cinturões Orogênicos datados do Ciclo Brasiliano. Este evento é caracterizado pelo desenvolvimento de um orógeno contracional com transporte de massa de SE para NW, seguido de uma distensão regional com o posicionamento de domos granito-gnáissico (CPRM, 2005). A geometria do QF é definida por mega dobras sinformes e antiformes truncadas por cinturões de falhas de empurrão norte-sul, na sua parte oriental. Seus limites são marcados a norte pelo homoclinal da Serra do Curral, a oeste pela Sinclinal Moeda, ao sul pela Sinclinal Dom Bosco e a leste, pela Sinclinal Santa Rita. 


\section{Referencial Teórico}

As análises morfométricas e geomorfométricas tornaram-se de grande valia na quantificação e caracterização do relevo, sobretudo com a bacia hidrográfica como unidade espacial de análise (HORTON, 1945; STRAHLER, 1957; STRAHLER, 1952; CHORLEY, 1962; CHORLEY e KENNEDY, 1971; CHRISTOFOLETTI, 1980; HACK, 1973). Neste contexto, observa-se que a aplicação dos índices morfométricos, propostos com o objetivo inicial de aplicação prática na análise do comportamento hidrológico de bacias hidrográficas, é também amplamente utilizado para a avaliação da distribuição espacial de padrões de formas de relevo e na análise da evolução geomorfológica de bacias de drenagem.

Evans (1972) enfatiza a importância de acrescentar o prefixo Geo ao termo, morfometria, que por sua vez é corriqueiramente mais usado na literatura. O prefixo seria necessário para distinguir a mensuração das formas modeladas por processos geomorfológicos das demais mensurações de formas encontradas na natureza. Ainda segundo Evans (op. cit) a Geomorfometria fornece subsidio para a análise geomorfológica, contribuindo, por exemplo, para a avaliação da distribuição espacial de padrões de formas.

A técnica mais comum de derivação dos atributos e subsequente cálculo dos parâmetros em ambiente digital é realizada a partir do uso dos Modelos Digitais de Elevação (MDE) e da rede hidrográfica digitalizada, obtidos de cartas topográficas, ortofotos ou imagens de sensores orbitais. Sobre esses dados são aplicadas rotinas computacionais para extrair os dados necessários à análise morfométrica.

Como exemplo de trabalhos encontrados na literatura sobre análises (Geo)morfométricas em ambiente SIG, podemos citar: Evans (1992); Santa Catarina (1997), Tucker et al. (2001), Valeriano e Morais (2001), Ganas et al (2005), Pike et al, 2009 e Evans (2012).

A aplicação de novas metodologias na extração dos atributos e cálculo dos parâmetros a partir dos MDEs se associa a outras técnicas de mensuração de feições (formas) e fenômenos (processos) da superfície terrestre, permitindo aos pesquisadores melhores resultados nas análises morfológicas e de evolução de relevo sustentadas em dados concretos e não apenas em hipóteses dedutivas (RUSZKICZAYRUDIGER, 2007; LOPES, 2008, WALCOTT e SUMMERFIELD, 2007; EVANS, 2012).

Para minimizar a subjetividade que se encontra nas metodologias quantitativas utilizadas em mapeamentos geomorfológicos, Sampaio (2008), propõe a utilização do Índice de Concentração da Rugosidade (ICR). Basicamente o índice delimita unidades de relevo levando em consideração padrões de rugosidade presentes na região. (SAMPAIO e AUGUSTIN, 2014).

Para Hobson (1972), a rugosidade é compreendida como a relação entre a área da superfície do terreno inclinada e a área da superfície do terreno reduzida ao plano, podendo ser esquematizada da seguinte 
OS DESAFIOS DA GEOGRAFIA FÍSICA NA FRONTEIRA DO CONHECIMENTO

Instituto de Geociências - Unicamp

Campinas - SP

28 de Junho à 02 de Julho de 2017

forma: Rugosidade $(\mathrm{R})=(\mathrm{Si}$ ou área da vertente $) /(\mathrm{Sp}$ ou superfície reduzida ao plano). Este índice vem sendo utilizado no auxílio de mapeamentos geomorfológicos em várias escalas de análise, alcançando excelentes resultados (SAMPAIO e AUGUSTIN, 2014). O ICR, portanto, pode ser utilizado para indicar a capacidade erosiva da rede de drenagem para esculpir o relevo (dissecação).

O ICR baseia-se na análise tridimensional do relevo, como no processamento matemático dos pixels contidos em um MDE. Porém, ao contrário desta técnica em que cada pixel é quantificado individualmente, o ICR possibilita representar unidades homogêneas de relevo. Deste modo, pode-se dizer que o ICR é a soma dos valores de declividade dos pontos existentes em uma determinada área, em que a quantidade de pontos é determinada pela resolução espacial do MDE.

O Índice de Hack (Stream Length-Gradient Index) ou Índice SL, denominado por Etchebehere et al. (2004) "Relação Declividade-Extensão", foi concebido por John T. Hack e apresentado em Hack (1973). Passível de ser obtido com relativa facilidade e agilidade, o índice foi amplamente utilizado na literatura acadêmica por oferecer base comparativa entre rios de diferentes extensões e características fisiográficas, além de possibilitar inferências acerca da história e do desenvolvimento geológico e geomorfológico da área estudada.

Foi aplicado, por exemplo, por Mayer \& Wentworth (1983) para inferir movimentação da falha de Stafford - nordeste do Estado da Virgínia - EUA; por Keller (1977) e Keller \& Rockwell (1984) para a identificação de "células tectônicas" de grande atividade em partes da Califórnia - EUA; por Seeber \& Gornitz (1983) para a deteç̧ão de atividade neotectônica no Himalaia; por McKeown et al. (1988) para inferir a expressão fisiográfica de uma série de registros sísmicos na região montanhosa de Ozark, Estado do Arkansas-EUA; por Etchebehere et al. (2004) e Etchebehere et al. (2006) para a identificação de deformações neotectônicas no Vale do Rio Peixe - Estado de São Paulo; por Troiani \& Della Seta (2008) para análise morfotectônica de pequenas bacias na região central da Itália, entre muitos outros exemplos.

$\mathrm{Na}$ última década este índice foi amplamente utilizado no Brasil, como um indicador e um auxiliar em pesquisas sobre neotectônica, sob forte influência dos trabalhos de Etchebehere et al. (2004, 2006). Os resultados do índice SL são relacionados, pelos autores que o analisam sob a perspectiva da neotectônica, à condições anômalas do canal de drenagem.

O índice SL foi utilizado por Fonseca (2010) e Fonseca e Augustin (2011) para a análise morfométrica e morfológica de bacias de drenagem na serra do Espinhaço Meridional-MG, como forma de analisar a dinâmica energética das bacias hidrográficas da região. Bezerra (2014) utilizou o índice SL para avaliar a energia da rede de drenagem e estabelecer relações com a erosão diferencial no processo de evolução do relevo do Quadrilátero Ferrífero. Neste trabalho, o índice SL é utilizado como um indicador do vigor energético dos canais de drenagem, uma variável morfométrica relacionada ao processo de dissecação e evolução do relevo (FONSECA, 2010; FONSECA e AUGUSTIN, 2011; BEZERRA, 2014). 
OS DESAFIOS DA GEOGRAFIA FÍSICA NA FRONTEIRA DO CONHECIMENTO Instituto de Geociências - Unicamp

Campinas - SP

28 de Junho à 02 de Julho de 2017

A densidade de drenagem constitui-se em um dos principais parâmetros na análise morfométrica de bacias hidrográficas, conceituada pelo IBGE (2009) como a relação entre o comprimento total dos canais e a área amostrada. A densidade de canais é referente à quantidade de canais existentes por área. Estes parâmetros, definidos inicialmente por Horton (1945), permitem apresentar um comportamento hidrológico influenciado pela litologia e estrutura geológica, bem como, por outros parâmetros do meio físico (HIRUMA e PONÇANO, 1994).

No presente trabalho a densidade de drenagem foi utilizada como um indicador de zonas anisotrópicas do relevo, onde ocorrem processos erosivos mais intensos e a consequente retomada erosiva das forma de relevo, processos com estreita correlação espacial com a dissecação (KIRKIBY, 1987; MONTGOMERY e DIETRICH, 1989; HIRUMA e PONÇANO, 1994; OGUCHI , 1997; SILVA et al, 2010).

\section{Materiais e Procedimentos Metodológicos}

\subsection{Dados Topográficos}

Para a aquisição dos dados morfométricos da área de estudo, foi realizado o processo de mosaicagem de duas imagens Shuttle Radar Topography Mission - SRTM (Projeto TOPODATA/INPE, 2011 folhas 19S45-20S45), de resolução espacial de 30m, posteriormente convertidas em 90 metros, com o objetivo de agilizar o processamento, mas sem perda de informação devido a escala geográfica da área de estudo e a escala cartográfica do produto final. A rede hidrográfica utilizada para gerar o índice de Hack e a densidade de drenagem e os demais dados vetoriais foram obtidos através do website do Zoneamento Ecológico Econômico de Minas Gerais - ZEE/MG.

\subsection{Obtenção do ICR Global}

A obtenção do ICR Global se deu, primeiramente, com a transformação do modelo digital de elevação (MDE), obtido através das imagens SRTM, em valores de declividade em porcentagem (\%). Posteriormente, $\mathrm{O}$ dado matricial da declividade foi convertido para o formato de pontos. Em cada ponto atribuiu-se o valor do pixel de origem para permitir a aplicação do Estimador de Densidade por Kernel, executado através do software Arcgis 10.1. Esta ferramenta de interpolação traça uma vizinhança circular ao redor da cada ponto amostrado em função do raio de influência estipulado. Salienta-se que valores maiores para o raio de busca condicionam uma varredura mais generalizada enquanto valores menores condicionam resultados mais detalhados. O raio de busca estipulado para a aquisição do ICR Global foi de $3.000 \mathrm{~m}$, que abrange aproximadamente uma área de $28 \mathrm{Km}^{2}$. 


\section{OS DESAFIOS DA GEOGRAFIA FÍSICA NA FRONTEIRA DO CONHECIMENTO Instituto de Geociências - Unicamp \\ Campinas - SP \\ 28 de Junho à 02 de Julho de 2017}

Os valores encontrados foram agrupados em 5 classes de intervalos utilizando o método de quebras naturais (Natural Breacks.), após realização de testes para averiguar a representação da área e posteriormente normalizados em ambiente SIG, por operação de álgebra de mapas. A operação é efetuada pela divisão da matriz resultante pelo número de pixels computados, conforme expressão a seguir, obtendo-se valores entre 0 e 1 :

$$
f(x)=\frac{X-\operatorname{Min}}{\operatorname{Max}-\operatorname{Min}}
$$

Onde, $\boldsymbol{X}$ corresponde ao raster resultante dividido pela diferença de seus valores máximo e mínimo.

De acordo com Augutin e Sampaio (2014), a resolução espacial do MDE influência nos valores do ICR em função da quantidade de pontos somados por unidade de área. Portanto, a normalização tem o intuito de padronizar os valores obtidos, a fim de possibilitar comparações entre diferentes estudos, independente da resolução espacial do MDE de origem. O processo realizado para a aquisição do mapa de ICR é apresentado na Figura 1:

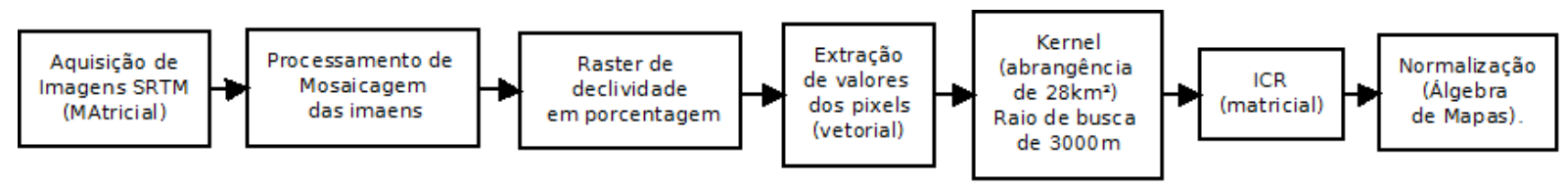

Figura 1 - Fluxograma da obtenção do ICR Global

\subsection{Obtenção do Índice de Hack}

O índice de Hack pode ser calculado a partir da seguinte expressão:

$$
S L=\frac{\Delta H}{\Delta L} L
$$

Onde $L$ representa o comprimento do segmento considerado desde seu mais longo alcance, $\Delta H$ representa a variação altimétrica do segmento considerado e $\Delta L$ representa a distância horizontal do mesmo. O produto SL também pode ser obtido segundo a seguinte fórmula:

$$
S L=\frac{\Delta H}{\log _{e} L_{2}-\log _{e} L_{1}}
$$

A obtenção do $\Delta H$ dos segmentos hierarquizados da rede hidrográfica, conforme método de Strahler (1957), foi realizada por um processo de estatística zonal utilizando o software Arcgis 10.1, onde define-se a forma e os locais das zonas, no caso, os segmentos da rede hidrográfica, para então extrair os dados altimétricos de um MDE. A zona corresponde a um conjunto de células de um raster 
OS DESAFIOS DA GEOGRAFIA FÍSICA NA FRONTEIRA DO CONHECIMENTO

Instituto de Geociências - Unicamp

Campinas - SP

28 de Junho à 02 de Julho de 2017

que possuem o mesmo valor. Os valores de $\Delta \mathrm{L}$ foram calculados em metros e posteriormente transformados em escala semi-logarítimica, visando evitar resultados com muitas casas decimais, o que dificulta o entendimento do índice.

Os segmentos com os Índices de Hack de valores menores que 1 foram excluídos por serem desprezíveis para uma análise regional. Os demais segmentos foram convertidos para o formato de pontos para aplicação do interpolador IDW (Inverse Distance Weighting) e assim permitir a espacialização de forma continua dos pontos, demonstrando as regiões com maior vigor energético. De acordo com Fonseca (2010), o IDW pondera as informações pontuais durante o processo de interpolação, onde um ponto possuirá menos influência sobre outro em decorrência do aumento da distância entre eles. O IDW pode ser representado pela seguinte expressão:

$$
z=\frac{\sum_{i=1}^{n} \frac{1}{d_{i}} z_{i}}{\sum_{i=1}^{n} \frac{1}{d_{i}}}
$$

Onde $\boldsymbol{z}$ corresponde aos valores estimados, $\mathbf{n}$ representa o número de amostras, $\boldsymbol{z} \boldsymbol{i}$ os valores conhecidos, e $\boldsymbol{d i}$ representam as distâncias entre os valores conhecidos e estimados (zie $z$ ). A Figura 2 representa o processo para a aquisição do referente índice:

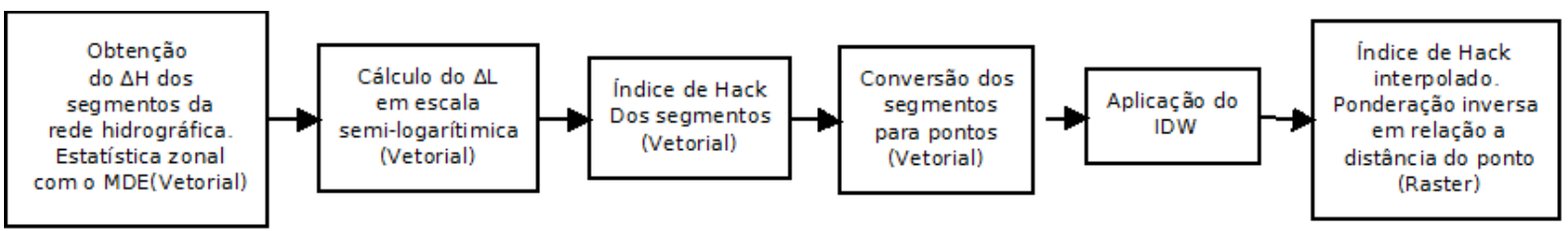

Figura 2 - Fluxograma da obtenção do Índice de Hack

\subsection{Aquisição da Densidade de Drenagem}

O processo para a aquisição da densidade de drenagem se deu com a aplicação do Estimador de Densidade por Kernel em diferentes contextos, embasados em três atributos da rede hidrográfica: a ordem 1 dos canais, o comprimento dos canais e a última, apenas a quantidade de canais. Foram utilizadas na execução do Kernel as mesmas configurações adotas para extrair o ICR Global.

\section{5. Índice Global de Dissecação do Relevo - IGDR}

A criação do índice se deu a partir do processo de álgebra de mapas com os rasters de ICR Global, Índice de Hack e Densidade de Drenagem, que teoricamente correspondem à atuação dos processos hidrogeomorfológicos e morfoesculturais nas formas existentes do relevo. Logo, o IGDR funciona como 


$\begin{aligned} & \text { XVII Simpósio Brasileiro } \\ & \text { de Geografia Fisica Aplicada }\end{aligned}$
$\begin{aligned} & \text { I Congresso Nacional } \\ & \text { de Geografia Física }\end{aligned}$

uma indicação do potencial dos processos erosivos na paisagem. Os produtos gerados nas etapas anteriores foram normalizados para permitir a interação de variáveis com unidades de medida distintas. A expressão utilizada é descrita a seguir:

$$
\text { IGDR }=(\text { ICR Global } \times \mathbf{0 , 3 3})+(\mathrm{IH} \times \mathbf{0 , 3 3})+(\text { Den. Dre } \times \mathbf{0 , 3 3})
$$

Observa-se que os índices possuem o mesmo peso na expressão, não havendo uma influência maior de algum índice no raster resultante. Os valores do raster variam entre 0 e 1,0.

\section{Resultados e Discussão}

A Figura 3 corresponde aos resultados dos índices preliminares da metodologia proposta (Índice de Concentração da Rugosidade, Índice de Hack e Densidade de Drenagem). Ao analisá-los, percebe-se a potencialidade de obtenção de padrões importantes a respeito das características físicas da região a partir de informações quantitativas.
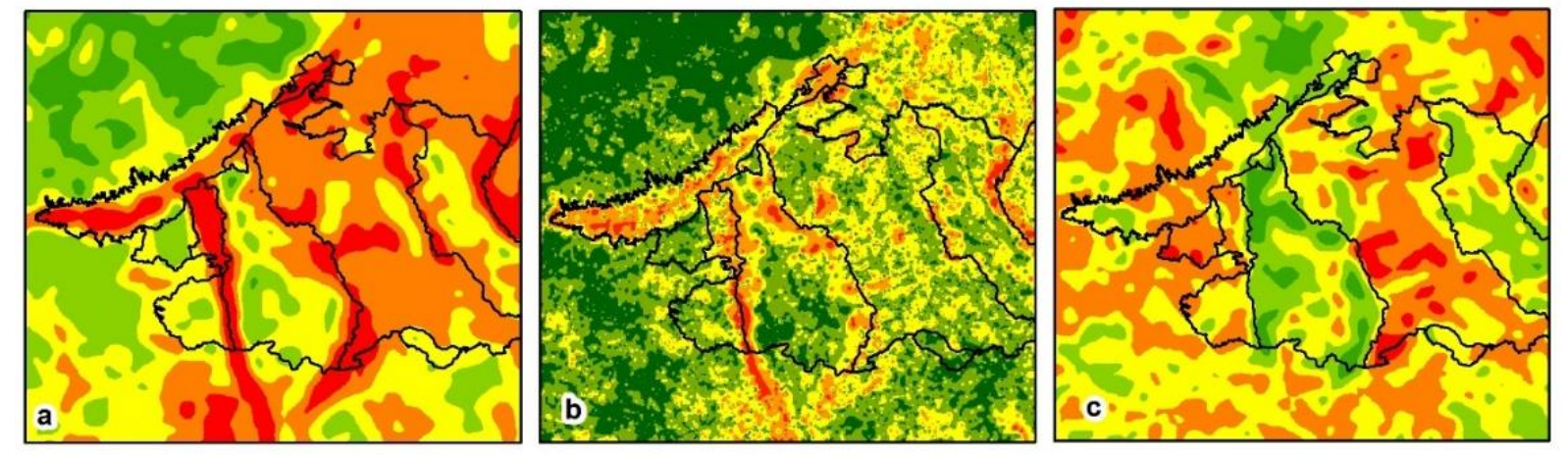

Figura 3 - Índices intermediários. (a) ICR Global, (b) Índice de Hack, (c) Densidade de drenagem. A intensidade dos índices varia de muito alta (vermelho) e muito baixa (verde escuro). As delimitações correspondem as unidades morfoestruturais mapeadas pelo CPRM (2005).

Com o ICR Global é possível distinguir padrões de acordo com o nível de dissecação do relevo, podendo também associa-lo ao grau da influência morfoescultural da paisagem. A aplicação do raio de busca sugerido por Augutin e Sampaio (2014), proporcionou um resultado satisfatório ao compará-lo com as unidades morfoestruturais da APA Sul RMBH mapeadas pelo CPRM (2005), uma vez que em um recorte regional coincidiu com os limites das unidades de alto contraste morfológico. Assim, áreas com o relevo mais acidentado estão representadas por cores quentes, como a Crista Homoclinal da Serra do Curral, enquanto áreas de relevo mais suavizado estão representadas por tonalidades de verde, a exemplo, o Platô Sinclinal Moeda.

A distribuição espacial do Índice de Hack, por sua vez, evidenciou que vigor energético da rede de drenagem se encontra principalmente nos segmentos de drenagem que tem fluxo hídrico começando nas serras que delineiam o Quadrilátero Ferrífero. Portanto, pode-se associar o forte vigor energético às 
OS DESAFIOS DA GEOGRAFIA FÍSICA NA FRONTEIRA DO CONHECIMENTO Instituto de Geociências - Unicamp

Campinas - SP

28 de Junho à 02 de Julho de 2017

cristas dos planaltos, por se tratarem de áreas de alta declividade/rugosidade. Muitos pontos correspondem a vertentes escarpadas que possuem uma alta amplitude altimétrica entre as nascentes dos canais e seus pontos de deságue.

A densidade de drenagem é outro importante parâmetro para distinção das características morfológicas, uma vez que é possível visualizar a influência da geologia na formação da paisagem da região. Este índice foi ponderado pela quantidade de canais de drenagem existentes na área de estudo. Deste modo, sua distribuição espacial resultou em manchas graduais de altas a baixas densidades, independente das características dos canais como comprimento dos corpos hídricos. O índice evidenciou principalmente a baixa concentração de drenagem no Platô do Sinclinal Moeda e do Patamares Escalonados do Jaguara em relação as demais unidades.

A Figura 4, a seguir, é o resultado da aplicação do Índice Global de Dissecação do Relevo. Este índice não leva em consideração apenas as formas, mas também a dinâmica hidrogeomorfológica e a sua intensidade ao atuar no modelado das feições. O IGDR, permite avaliar a maior ou menor influência dos agentes modeladores do relevo, podendo também delimitar regiões a partir de sua estabilidade geomorfológica. A Figura 5 apresenta as Unidades Morfoestruturais da APA Sul RMBH.

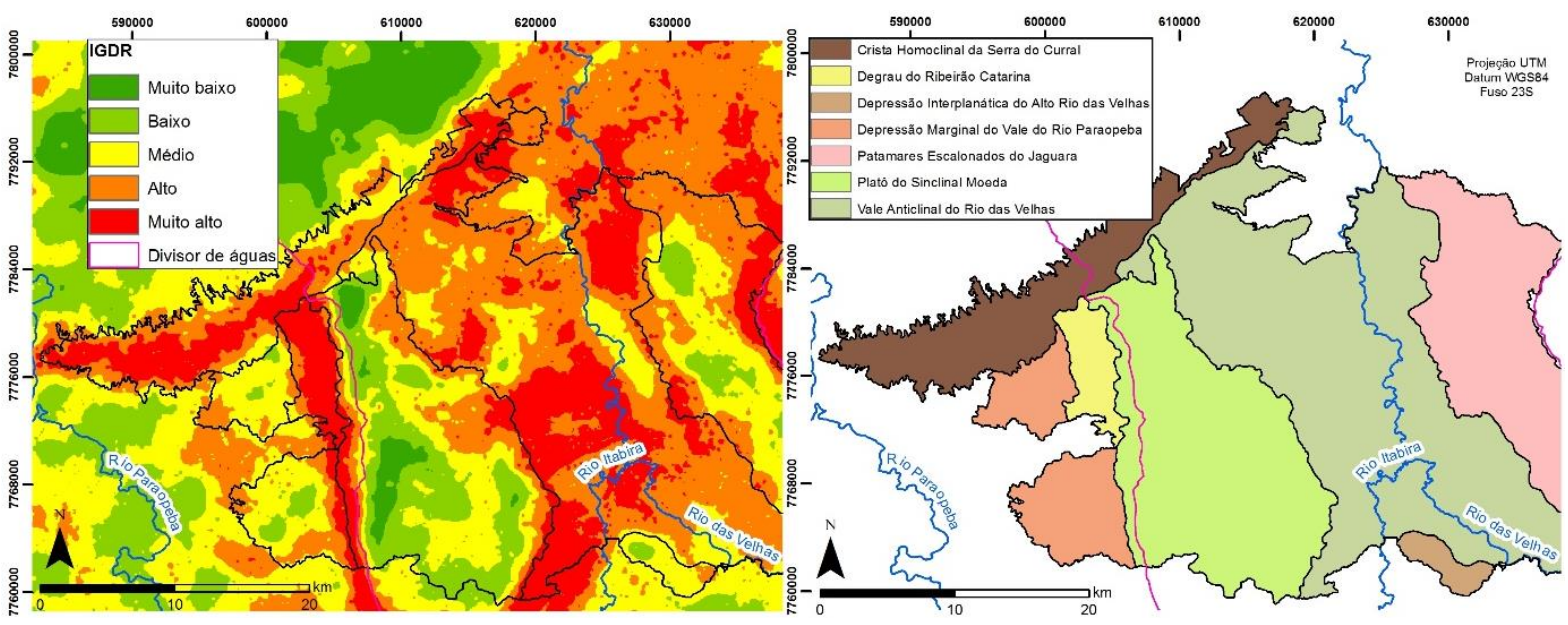

Figura 4 - Índices Global de Potencialidade de Dissecação do Relevo. Figura 5 - Unidades Morfoestruturais da APA Sul RMBH.

A Tabela 1 apresenta os valores da aplicação do IPDR Global na área de interesse. Conforme a tabela, as classes alta e muito alta possuem maior representatividade na região em relação as classes mais baixas, com aproximadamente $39 \%$ da área total estudada contra $33 \%$. Aproximadamente $28 \%$ possui potencial moderado para a evolução do relevo com base na dissecação. Pode-se inferir a partir dos dados uma distribuição equilibrada entre os níveis de dissecação na área de estudo. 


\section{OS DESAFIOS DA GEOGRAFIA FÍSICA NA FRONTEIRA DO CONHECIMENTO Instituto de Geociências - Unicamp \\ Campinas - SP \\ 28 de Junho à 02 de Julho de 2017}

Tabela I - Valores das Classes do IPDR Global

\begin{tabular}{|c|c|c|}
\hline $\begin{array}{c}\text { Classes do IPDR } \\
\text { Global }\end{array}$ & $\begin{array}{c}\text { Intervalos } \\
\text { normalizados }\end{array}$ & Proporção (\%) \\
\hline Muito baixa & $0,0307-0,232$ & 9,3 \\
\hline Baixa & $0,233-0,301$ & 23,2 \\
\hline Média & $0,302-0,361$ & 28,4 \\
\hline Alta & $0,362-0,43$ & 27,3 \\
\hline Muito alta & $0,431-0,703$ & 11,8 \\
\hline
\end{tabular}

Diante o resultado apresentado na Figura 4, notam-se padrões bem definidos de intensidade do índice, na qual suas bordas se aproximam da delimitação das unidades morfoestruturais mapeadas pelo CPRM. Áreas de cristas e de relevo acidentado, bem como áreas mapeadas como depressões obtiveram índices condizentes. Outro fator importante foi o aparecimento de feições, em diferentes proporções, não consideradas pelo mapeamento morfoestrutural convencional, mesmo utilizando dados ajustados para mapeamento em escala regional. A exemplo temos porções classificadas como intensidade média no Vale Anticlinal do Rio das Velhas e áreas de alta intensidade que extrapolam a borda leste do Platô do Sinclinal Moeda.

\section{Considerações Finais}

O mapa de Índice Global de Dissecação do Relevo é uma proposta para apresentar compartimentos geomorfológicos não como formas estáticas, mas como modelados que se encontram em desenvolvimento em função de processos geomorfológicos dinâmicos, que atuam em diferentes escalas temporais. Portanto, é válida sua criação, em vista da necessidade de compor modelos geomorfológicos cada vez mais condizentes com a realidade.

Em relação aos resultados obtidos, estes demonstraram-se satisfatórios dentro da escala de mapeamento proposta, apresentando boa precisão na delimitação das unidades ao compará-lo com o mapeamento realizado pelo CPRM. Também demonstrou-se eficiente na detecção de variações significativas na intensidade da dissecação dentro das unidades.

Ressalta-se que a metodologia aqui apresentada pode ser aplicada em escalas locais, como deduziram Augustin e Sampaio (2014) para o Índice de Concentração da Rugosidade. A aplicação em outras escalas dependem da resolução espacial do MDE, do comprimento do raio de abrangência do Estimador de Densidade de Kernel para a extração das densidades dos atributos e do nível de detalhe da base cartográfica da rede de drenagem. No entanto, não exclui a necessidade de visitas a campo e a análise de outras variáveis que influenciam na modelagem do relevo. 


\section{Bibliografia}

AUGUSTIN, C. H. R. R. e SAMPAIO, T. V. M. Índice de Concentração da Rugosidade: Uma nova proposta metodológica para o mapeamento e quantificação da dissecação do relevo como subsídio a cartografia geomorfológica. Revista Brasileira de Geomorfologia, v-15, n¹, 2014.

BEZERRA, D. P.; AUGUSTIN, C. H. R. R. Quadrilátero Ferrífero - MG : fatores controladores do relevo. Dissertação (mestrado), UFMG, 2014. 148 f.

CHORLEY, R. J. Geomorphology and general systems theory. USGS, Professional paper 500 B, 1962. (tradução em Notícia Geomorfológica, v. 22, n. 23, 1971. p. 3-22)

CHORLEY, R. J.; KENNEDY, B. A. Physical geography: a systems approach. Englewood Cliffs: Prentice Hall, 1971.

CHRISTOFOLETTI, A. Geomorfologia. São Paulo: Edgard Blücher, 1980, 186p.

ETCHEBEHERE, M. L. C.; SAAD, A. R.; PERINOTTO, J.A.J.; FULFARO, V.J. Aplicação do Índice "Relação Declividade-Extensão - RDE" na Bacia do Rio do Peixei (SP) para deteç̧ão de deformações neotectônicas, Revista do Instituto de Geociências da USP - Série Científica, v.4, n.2, p. 43-56, 2004.

ETCHEBEHERE, M. L. C.; SAAD, A. R.; SANTONI, G.; CASADO, F. C.; FULFARO, V. J. Detecção de prováveis deformações neotectônicas no vale do rio do Peixe, Região Ocidental Paulista, mediante aplicação de índices RDE (Relação Declividade-Extensão) em segmentos de drenagem. Revista UNESP - Geociências, v.25, n. 3, p.271-287, 2006.

EVANS. I. S. General geomorphometry, derivates of altitude, and descriptive statistics. 18-90, 1972. in: CHORLEY, R.J. Spatial Analysis in Geomorphology. London, British Geomorphological Research Group, 1972. $391 \mathrm{p}$.

EVANS, Ian S. Geomorphometry and landform mapping: What is a landform?. Geomorphology, v. 137, n. 1, p. 94-106, 2012.

FLORENZANO, T.G. (org.). Geomorfologia: conceitos e tecnologias atuais. São Paulo: Ofícina de Textos, 2008. 320p.

FONSECA, B. M. O uso do sistema de informações geográficas na análise morfométrica e morfológica de bacias de drenagem na Serra do Espinhaço Meridional-MG. Dissertação de Mestrado. IGC - UFMG. Belo Horizonte. 2010. 93 p.

FONSECA, B. M.; AUGUSTIN, C.H.R.R. Use of GIS to calculate Hack Index as a basis for comparative geomorphologic analysis between two drainage basins: a case study from SE-Brazil. In: International Geographic Union Regional Geographic Conference-UGI. 2011. p. 1-12.

GANAS, A.; PAVLIDES, S.; KARASTATHIS, V. DEM-based morphometry of range front escarpments in Attica central Greece, and its relation to fault slip rates. Geomorphology. Elservier, v.65, p. 301-319, 2005

HACK, J. T. Stream-profile analysis and stream-gradient index. Journal of Research of the United States Geological Survey, v. 1, n. 4, p. 421-429, 1973.

HIRUMA, Silvio Takashi; PONÇANO, Waldir Lopes. Densidade de drenagem e sua relação com fatores geomorfopedológicos na área do alto Rio Pardo-SP e MG. Revista do Instituto Geológico, v. 15, n. 1/2, 1994.

HORTON, R.E. Erosional development of streams and their drainage basins: hydrophysical approach to quantitative morphology. Bulletin of the Geological Society of America Bull. n.56.1945.

IBGE. Manual técnico de geomorfologia. Manuais técnicos em geociências n. 5. Coordenação de Recursos Naturais e Estudos Ambientais. - 2. ed. - Rio de Janeiro : IBGE, 2009. 182 p.

KELLER, E.A. Adjustment of drainage to bedrock in regions of contrasting tectonic framework [abs.]: Geological Society of America Abstracts with Programs, v. 9, no. 7, 1977. p. 1046.

KELLER, E.A., and Rockwell, T.K.Tectonic geomorphology, Quaternary chronology, and paleoseismicity, in COSTA, J.E., AND FLEISHER, P.l, eds., Developments and applications of geomorphology: New York, 1984. Springer-Verlag, p. 203-239. 
OS DESAFIOS DA GEOGRAFIA FÍSICA NA FRONTEIRA DO CONHECIMENTO

Instituto de Geociências - Unicamp

Campinas - SP

28 de Junho à 02 de Julho de 2017

KIRKBY, M. J. Modelling some influences of soil erosion, landslides and valley gradient on drainage density and hollow development. Geomorphological models: theoretical and empirical aspects/Frank Ahnert (editor), 1987.

LOPES, M. R. S. Avaliação das taxas de recuo diferencial do divisos Doce-São Francisco na borda leste do Quadrilátero Ferrífero:aplicação de isótopos cosmogênicos, 2008. Projeto de Tese (Doutorado em Geografia) Departamento de Geografia,Universidade Federal do Rio de Janeiro, Rio de Janeiro.

MAYER, L., WENTWORTH, C.M. Geomorphic differences east and west of the Stafford fault system, northeastern Virginia [abs.]: Southeastern Section, Geological Society of America, 1983. v. 15, no. 2, p. 56.

MCKEOWN, F. A.; JONES:CECIL, M.; ASKEW, B. L.; McGRATH, M. B. Analysis of stream-profile data and inferred tectonic activity, Eastern Ozark Mountains region. U. S. Geological Survey Bulletin, n. 1807, 1988.

MONTGOMERY, D. R.; DIETRICH, W. E. Source areas, drainage density, and channel initiation. Water Resources Research, v. 25, n. 8, p. 1907-1918, 1989.

OGUCHI, T. Drainage density and relative relief in humid steep mountains with frequent slope failure. Earth Surface Processes and Landforms, v. 22, n. 2, p. 107-120, 1997.

PIKE, R. J.; EVANS, I. S.; HENGL, T. Geomorphometry: a brief guide. Developments in Soil Science, v. 33, p. 3-30, 2009 .

Projeto APA Sul RMBH: Geologia estrutural / Orivaldo F. Baltazar, Márcia Zuchetti - Belo Horizonte SEMAD/CPRM, 2005

Projeto APA Sul RMBH: Geomorfologia / Medina A. I. M; Dantas M. E.; Saadi A. - Belo Horizonte SEMAD/CPRM, 2005.

RODRIGUES, C. Geomorfologia aplicada: avaliação de experiências e de instrumentos de planejamento territorial e ambiental brasileiros. Universidade de São Paulo, 1997. 279 p.

RUSZKICZAY-RUDIGER, Z. Tectonic and climatic forcing in Quaternary landscape evolution in the central Pannonian Basin:A quantitative geomorphological geochronological and structural analysis.2007. 149p. Tese (Doutorado em Ciências Naturais) Vrije University, Amsterdã, 2007.

SANTA CATARINA. Secretaria de Estado do Desenvolvimento Urbano e Meio Ambiente, Secretaria de Estado do Desenvolvimento Rural e da Agricultura. Zoneamento da disponibilidade e da qualidade hídrica. Plano de gestão e gerenciamento da bacia do rio Araranguá. Florianópolis : SDM - Instituto Cepa, v. 3, 62p, 1997.

SEEBER, L., GORNITZ, V.M. River profiles along the Himalayan arc as indicators of active tectonics: Tectonophysics, 1983 . v. 92, p. 335-367.

SILVA, D. G.; MELO, R. F. T.; BARROS, A. C C.. A influência da densidade de drenagem na interpretação da evolução geomorfológica do complexo de tanques do município de Brejo da Madre de DeusPernambuco, nordeste do Brasil. Revista de Geografia (Recife), v. 26, n. 3, p. 294-306, 2010.

STRAHLER, A,N. Dynamic basis of geomorphology. Bull. Geol. Soc. Am., v.63. New York, 1952. 188 p.

STRAHLER, Arthur N. Quantitative analysis of watershed geomorphology. Eos, Transactions American Geophysical Union, v. 38, n. 6, p. 913-920, 1957.

TROIANI, F. \& DELLA SETA, M. The use of the Stream Length-Gradient index in morphotectonic analysis of small catchments: A case study from Central Italy. Geomorphology, 2008.

TUCKER, G. E.; Catani, F.; Rinaldo, A. Brás, R. L., Statistical analysis of drainage density from digital terrain data. Geomorphology. Elservier, v.36, p.187-202, 2001.

VALERIANO, M. M.; MORAES, J. F. L. Extração de rede de drenagem e divisores por processamento digital de dados topográficos. Simpósio Brasileiro de Sensoriamento Remoto, 10, Foz do Iguaçu, 2001. Anais...São José dos Campos:INPE, 2001.

WALCOTT, R. C.; SUMMERFIELD, M. A. Scale dependence of hypsometric integrals: an analysis of southeast African basins. Geomorphology. p.174-186, 2007. 